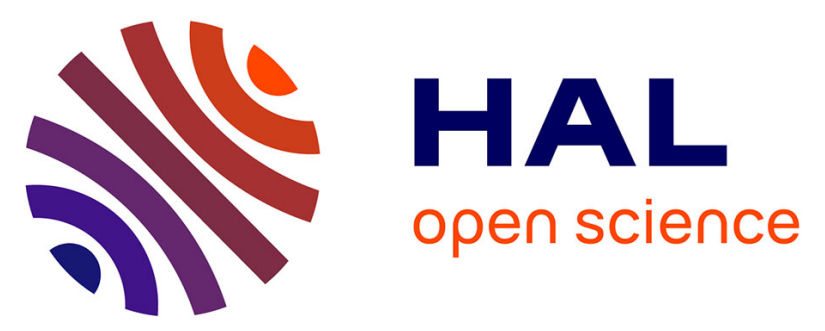

\title{
Performance of a new rapid test for the detection of hepatitis B surface antigen in various patient populations.
}

Stéphane Chevaliez, Dominique Challine, Habiba Naija, Tony C. Luu, Syria Laperche, Lourdes Nadala, Jean-Pierre Allain, Helen H. Lee, Jean-Michel Pawlotsky

\section{To cite this version:}

Stéphane Chevaliez, Dominique Challine, Habiba Naija, Tony C. Luu, Syria Laperche, et al.. Performance of a new rapid test for the detection of hepatitis B surface antigen in various patient populations.. J Clin Virol, 2014, 59 (2), pp.89-93. 10.1016/j.jcv.2013.11.010 . inserm-00950145

\section{HAL Id: inserm-00950145 https://www.hal.inserm.fr/inserm-00950145}

Submitted on 21 Feb 2014

HAL is a multi-disciplinary open access archive for the deposit and dissemination of scientific research documents, whether they are published or not. The documents may come from teaching and research institutions in France or abroad, or from public or private research centers.
L'archive ouverte pluridisciplinaire HAL, est destinée au dépôt et à la diffusion de documents scientifiques de niveau recherche, publiés ou non, émanant des établissements d'enseignement et de recherche français ou étrangers, des laboratoires publics ou privés. 


\section{CONFLICT OF INTEREST DISCLOSURE}

T.L. and L.N. are scientists employed by Diagnostics for the Real World Ltd (DRW); H.L, in addition to her academic position, is also the President and CEO of DRW. The other authors have no conflict of interest to disclose. 


\section{Performance of a New Rapid Test for the Detection of}

\section{Hepatitis B Surface Antigen in Various Patient Populations}

Stéphane Chevaliez, ${ }^{1,2 \#}$ Dominique Challine, ${ }^{1,2}$ Habiba Naija, ${ }^{1}$ Tony C Luu, ${ }^{3}$ Syria Laperche, ${ }^{4}$ Lourdes Nadala, ${ }^{3}$ Jean-Pierre Allain, ${ }^{5}$ Helen H. Lee, ${ }^{3,6}$ and Jean-Michel Pawlotsky ${ }^{1,2}$

${ }^{1}$ National Reference Center for Viral Hepatitis B, C and Delta, Department of Virology, Hôpital Henri Mondor, Université Paris-Est, Créteil, France; ${ }^{2}$ INSERM U955, Créteil, France; ${ }^{3}$ Diagnostics for the Real World Ltd., Sunnyvale, California; ${ }^{4}$ National Reference Center for Viral Hepatitis B, C and Delta in Blood Transfusion, Institut National de la Transfusion Sanguine, Paris, France; ${ }^{5}$ Division of Transfusion Medicine, Department of Hematology, University of Cambridge, Cambridge, United Kingdom; ${ }^{6}$ Diagnostics Development Unit, Department of Hematology, University of Cambridge, Cambridge, United Kingdom

\section{RUNNING TITLE: RDT for HBsAg detection}

Word count: 2499

Abstract: 249 words

\#Correspondent footnote: Dr Stéphane Chevaliez, Department of Virology, Hôpital Henri Mondor, 51 avenue du Maréchal de Lattre de Tassigny, 94010 Créteil, France. Tel: +33-1-4981-2828; Fax: +33-1-4981-2839. E-mail: stephane.chevaliez@hmn.aphp.fr 


\section{ABSTRACT}

3 Background: Rapid diagnostic tests (RDT) have been developed for the detection of

4 hepatitis B surface antigen (HBsAg). They represent a promising alternative to enzyme

5 immunoassays and a powerful tool for large-scale screening and diagnosis of HBV

6 infection, especially in regions without easy access to serological and molecular testing.

7 Objectives: The aims of the present study were to evaluate the characteristics and clinical

8 performance of a new CE-marked HBsAg RDT, DRW-HBsAg v2.0 assay (Diagnostics for the

9 Real World ${ }^{\mathrm{TM}}$, Ltd, USA), in various patient populations, including those chronically infected

10 with HBV, patients with severe acute hepatitis of unknown origin and pregnant women

11 with unknown HBV serological status at delivery. Results: The lower limit of detection of

12 the assay, evaluated in $\underline{21}$ clinical samples, ranged from $0.30 \pm 0.07$ to $0.97 \pm 0.26$

13 international units/mL (using Abbott Architect as a reference), depending on the HBV

14 genotype. The assay tested positive in $100 \%$ of patients with chronic hepatitis B, $96.3 \%$ of

15 HBsAg-positive acute hepatitis patients, and 95.2\% of HBsAg-positive pregnant women. Its

16 specificity was $98.8 \%$ in HBsAg-negative patients, $98.7 \%$ in HBsAg-negative patients with

17 acute hepatitis of unknown origin and 97.8\% in HBsAg-negative pregnant women. Amino

18 acid substitutions in the HBsAg major hydrophilic region did not affect HBsAg detection by

19 DRW-HBsAg v2.0. Conclusions: The new DRW-HBsAg v2.0 assay is a simple, rapid, easy-

20 to-run and highly sensitive assay that can be used in both high- and low-risk populations

21 for the diagnosis of HBsAg carriage. It appears to be a promising new tool for large-scale

22 screening and diagnosis of HBV infection. 


\section{BACKGROUND}

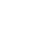

Approximately 240 million people are chronically infected with hepatitis B virus (HBV) worldwide. ${ }^{1}$ Each year, over 600,000 people die from HBV-related chronic liver disease through end-stage cirrhosis, liver failure and hepatocellular carcinoma (HCC). ${ }^{2}$ Hepatitis B is a global health problem, with geographic disparities in terms of prevalence. In high endemicity areas, $70 \%$ to $90 \%$ of the population becomes HBV-infected before the age of 40 , and $8 \%$ to $20 \%$ of individuals are chronic HBV carriers. In contrast, in low endemicity areas, the chronic carriage rate is less than $2 \%$.

Because chronic HBV infection is often asymptomatic, the vast majority of infected individuals are unaware of their liver disease, including in high medical standard areas. For instance, in France, more than $45 \%$ of infected individuals ignore their infection. ${ }^{3}$ Early diagnosis and treatment can reduce the risk of development of long-term complications and prevent further transmission. Hepatitis B surface antigen (HBsAg) is the key marker for screening and laboratory diagnosis of HBV infection. Rapid diagnostic tests (RDT) have been developed and widely used for viral infection screening. A high number of RDTs with satisfactory performance for the detection of antibodies to human immunodeficiency virus (HIV) have received product license in the United States and Europe. In contrast, very few rapid tests for HBsAg meet the analytical sensitivity of 0.130 international units (IU)/mL required by the regulatory authorities. Indeed, these RDTs in general lack the analytical sensitivity compared to enzyme immunoassays (EIA), the reference techniques for HBsAg detection in plasma or serum specimens. ${ }^{4}$ 
The aims of the present study were to evaluate the test characteristics and clinical performance of a newly developed HBsAg RDT, DRW-HBsAg v2.0 assay (Diagnostics for the Real World ${ }^{\mathrm{T}}$, Ltd, Sunnyvale, USA), in various populations of patients.

\section{STUDY DESIGN}

6

\section{Materials}

Plasma and serum samples were obtained from HBsAg-positive and -negative individuals with various conditions.

Group A was comprised of 335 HBsAg-negative individuals with different serological profiles for HBV infection, including no markers of past infection $(n=138)$, vaccination profile $(n=94)$, isolated anti-HBc antibodies $(n=29)$, or markers of resolved past infection $(n=74)$. Among them, 34 were HIV-seropositive and 48 were HCVseropositive.

Group B was comprised of 203 patients with chronic HBV infection, all of whom had quantifiable HBsAg by EIA (mean HBsAg titer: 3.85 $\pm 0.40 \log _{10}$ international units (IU)/mL; range: 2.40-5.10), anti-HBc antibodies, and detectable HBV DNA (mean HBV DNA level: 3.95 $\pm 1.45 \log _{10} \mathrm{IU} / \mathrm{mL}$; range: $\left.1.80-8.75\right)$. This group comprised 49 patients infected with HBV genotype A, 18 with genotype B, 23 with genotype C, 65 with genotype $D$, and 48 with genotype E.

Group C included 20 blood donors with chronic HBV infection infected with a dominant variant bearing one or several amino acid substitutions in the major hydrophilic region (MHR) containing the "a" determinant of the S gene. Among them, 3 were infected with HBV genotype A, 4 with genotype B, one with genotype C, 8 with genotype $\mathrm{D}$ and 4 
1 with genotype E. All had detectable/quantifiable HBsAg by EIA $\left(2.75 \pm 1.00 \log _{10} \mathrm{IU} / \mathrm{mL}\right.$;

2 range: -0.90 to 4.30 ) with one donor who had an HBsAg titer above the upper limit of

3 quantification of the assay ( $\left.>5,4 \log _{10} \mathrm{IU} / \mathrm{mL}\right)$. HBV DNA was detectable in $60.0 \%$ of them.

Group D was comprised of 408 patients with severe acute hepatitis; 27 of them had

\section{Laboratory measurements}

Serum HBsAg levels were quantified by means of the Architect HBsAg assay (Abbott Diagnostic, Chicago, Illinois), after a 1:100 dilution, as recommended by the manufacturer. The dynamic range of quantification of this assay is 0.05 to $250.0 \mathrm{IU} / \mathrm{mL}$. Samples with HBsAg levels $<0.05 \mathrm{IU} / \mathrm{mL}$ at 1:100 dilution were retested undiluted, while those with HBsAg $>250.0 \mathrm{IU} / \mathrm{mL}$ at 1:100 dilution were retested at a final dilution of 1:999, according to the manufacturer's instructions. The use of the Architect HBsAg assay as the reference test was justified by previous reports showing it is accurate, precise, reproducible and well calibrated to the World Health Organization (WHO) HBsAg standard.5, 6 We confirmed its good calibration by testing 5 members of the WHO HBsAg subtype adw2 genotype A reference panel (code: 03/262, NIBSC, UK) 5 times in two different experiments (data not shown). 
Serum HBV DNA levels were measured by means of a real-time PCR assay

$2\left(m 2000_{\mathrm{RT}} / m 2000_{\mathrm{SP}}\right.$, Abbott Diagnostic $) \cdot{ }^{7}$ Results were expressed in IU $/ \mathrm{mL}$. The lower limit

3 of detection of the assay is $15 \mathrm{IU} / \mathrm{mL}$.

The HBV genotype was determined by directly sequencing a portion of the

The DRW-HBsAg v2.0 assay is a new rapid immunochromatographic test for the qualitative detection of HBsAg that is performed manually. The test consists of a test strip (nitrocellulose membrane) and a single-use tube containing two lyophilized reagent beads. One reagent bead contains a hapten-labeled mouse monoclonal antibody to HBsAg (primary antibody), and the other contains a mouse monoclonal antibody to hapten conjugated to colloidal gold (secondary antibody). Eighty $\mu \mathrm{L}$ of human serum or plasma is added to the tube, which is then mixed gently before insertion of the test strip. The sample mixture flows up the test strip by capillary action, and the visual result is read after $30 \mathrm{~min}$. The development of a purple line in the test line region indicates the presence of HBsAg in the clinical specimen. The absence of a colored line indicates the absence of HBsAg or its presence at a concentration below the limit of detection of the test. Each test strip also incorporates a built-procedural control for reagent stability and test functionality, and indicates that the full reagents have properly flowed up the test strip. 
The test result is read visually according to the manufacturer's instructions.

2 However, in this study, an automatic readout by means of ESE-Quant Lateral Flow Reader

3 (ESE GmbH, Germany) was evaluated and compared with visually read results. The strips

4 were visually analyzed by two independent investigators and automatically with the ESE-

5 Quant Lateral Flow Reader. A cutoff optical density value of 20 was established with a

6 standard panel: an optical density value $<20$ indicated the absence of HBsAg, whereas

7 values $>25$ indicated the presence of HBsAg. A grey zone was defined between 20 and 25 .

8

\section{Statistical analysis}

Descriptive statistics are shown as the mean \pm standard deviation (SD). The sensitivities, specificities and the positive and negative predictive values of the RDT DRWHBsAg v2.0 for the detection of HBsAg were calculated.

\section{RESULTS}

\section{Analytical sensitivity in clinical samples of different HBV genotypes}

To determine the analytical sensitivity of the DRW-HBsAg v2.0 assay, serial dilutions of clinical samples from $\underline{21}$ patients from group B, infected with HBV genotypes A to $\underline{E}$, were tested once. The lower limit of detection was estimated as the lowest amount of HBsAg that could be detected by the DRW-HBsAg v2.0 assay. As shown in Table 1, the lower limit of detection of the assay ranged from $0.30 \pm 0.07 \mathrm{IU} / \mathrm{mL}$ to $0.97 \pm 0.26$ (using Architect HBsAg assay as a comparator), depending on the HBV genotype. 


\section{Specificity}

The specificity of the DRW-HBsAg v2.0 was assessed by testing the 335 clinical specimens from group A, the 381 HBsAg-negative samples from group D (acute hepatitis) and the 781 HBsAg-negative samples from group E (pregnant women at delivery).

Of the 335 HBsAg-negative specimens from group A, 4 tested HBsAg-positive with DRW-HBsAg v2.0 (specificity: 98.8\%; 95\% confidence interval [95\%CI], 96.9\%-99.5\%). Among these 4 false-positive results, two patients were HBV seronegative (no markers of past or ongoing infection), and two individuals had been vaccinated and harbored anti-HBs antibodies only. The serological status for HCV and HIV did not interfere with the specificity of the DRW-HBsAg v2.0 assay.

Among the 381 HBsAg-negative samples from patients with acute hepatitis of

unknown origin, there were 5 false-positive results with DRW-HBsAg v2.0 (specificity: 98.7\%; 95\%CI: 96.9\%-99.4\%). Among the 781 HBsAg-negative samples from pregnant women with unknown HBV status at delivery, there were 17 false-positive results with DRW-HBsAg v2.0 (specificity: 97.8\%; 95\%CI: 96.6\%-98.7\%). None of these individuals was HBsAg-positive in EIA (lower limit of detection: $0.05 \mathrm{IU} / \mathrm{mL}$ ) or HBV DNA-positive with real-time PCR (lower limit of detection: $15 \mathrm{IU} / \mathrm{mL}$ ).

\section{Clinical sensitivity, accuracy and influence of the HBV genotype}

Among 203 patients chronically infected with HBV genotypes A to E with detectable/quantifiable HBsAg by EIA and HBV DNA by real-time PCR, all tested positive for HBsAg by the DRW-HBsAg v2.0 assay (clinical sensitivity: 100\%; 95\%CI: 98.1\%-100\%). HBsAg was not detected by DRW-HBsAg v2.0 in one out of 27 patients with severe acute 
1 hepatitis ascribed to HBV due to the presence of HBsAg by EIA (sensitivity: 96.3\%; 95\%CI:

2 81.7\%-99.3\%). This patient was infected with HBV genotype D, HBsAg level was 0.32

$3 \mathrm{IU} / \mathrm{mL}$, anti-HBc IgM was present and HBV DNA level was $4.5 \log _{10} \mathrm{IU} / \mathrm{mL}$. Similarly, DRW-

4 HBsAg v2.0 failed to detect HBsAg in one out of 21 pregnant women found to be HBsAg-

5 positive by EIA (sensitivity: 95.2\%; 95\%CI: 77.3\%-99.1\%). This patient had an HBsAg level

6 of $0.70 \mathrm{IU} / \mathrm{mL}$. The presence of HBsAg was confirmed by two different EIA assays and

7 neutralized, and HBV DNA level was undetectable $(<15 \mathrm{IU} / \mathrm{mL})$.

8

\section{Influence of amino acid substitutions in HBsAg MHR}

Table 2 shows the amino acid positions with substitutions in the MHR in the 20 blood donors from group $\mathrm{C}$ identified as HBsAg mutants. HBsAg was detected in all of them by means of DRW-HBsAg v2.0, regardless of the amino acid substitution(s). A low signal was observed in one case, with an HBsAg titer of $0.13 \mathrm{IU} / \mathrm{mL}$.

\section{Comparison between visual and automatic readouts}

The results of the automated readout were compared to those obtained by visual analysis. Among 1,768 patients included in the study, $\underline{157}(\underline{8.9} \%)$ had discrepant results between visual and automatic readouts (Table 3). The test was interpreted as positive with both reading methods in all of the HBsAg-positive patients from group B (203 patients with chronic HBV infection), group C (20 blood donors infected with a dominant variant bearing substitutions in the MHR), group D (27 patients with severe acute hepatitis B) and group E (21 pregnant women with HBV infection). A false-positive result was obtained with the automated strip reader in $\underline{25}$ patients from group A, 63 patients from group D and 69 
1 pregnant women from group E. Only $\underline{8}$ out of 161 discrepant results fell within the gray

2 zone of the automated reader. All of them were HBsAg-negative with the Architect assay

3 and had undetectable HBV DNA with the $m 2000$ real-time PCR assay.

\section{DISCUSSION}

In the last 20 years, the availability and use of point-of-care (POC) tests have markedly increased and expanded to all fields of medicine. In the setting of infectious diseases, most existing POC tests consist of immunoassays, including agglutination or immunochromatographic strips (strip tests). These methods can be used to detect HBsAg. Other non-immunological POC tests based on nucleic acid detection and eventually quantification are currently in development. Rapid diagnostic tests remain promising alternatives to EIA-based methods. Indeed, they offer the advantages of simplicity, limited need for instrumentation, minimal training required, and rapid performance at room temperature. ${ }^{12}$ Therefore, these assays represent a powerful tool for large-scale screening and subsequent diagnosis. They are of particular value to improve access to care in regions without easy access to serological and molecular biology testing. They can also be used at the bedside or in remote care centers in any area of the world.

The results of the present study show that the newly developed DRW-HBsAg v2.0 rapid test has a better analytical sensitivity than other commercially available point-of-care HBV tests. Indeed, its lower limit of detection was <1.0 IU/mL of HBsAg, whereas among 19 HBsAg rapid assays recently tested, the lower limit of detection was $\geq 1.5 \mathrm{IU} / \mathrm{mL}$ in all cases and $>4.0 \mathrm{IU} / \mathrm{mL}$ in most of them. ${ }^{4}$ The analytical sensitivity required by regulatory agencies is $0.130 \mathrm{IU} / \mathrm{mL}$ of HBsAg, subtype adw2, genotype A (NIBSC 00/588). To obtain CE mark, 
1 the manufacturer has provided evidence for reaching the sensitivity requirement. In

2 addition, each lot of the DRW-HBsAg v2.0 assay was submitted to the Paul Ehrlich Institute

3 for sensitivity and specificity testing prior to its release and met the CE-mark requirement.

4 In the present work, the analytical sensitivity of DRW-HBsAg v2.0 in 23 clinical samples

5 ranging in genotype from $\mathrm{A}$ to $\mathrm{F}$ was slightly above this threshold, using the Architect

6 HBsAg assay as a reference. Our study also demonstrated the improved clinical sensitivity

7 of DRW-HBsAg v2.0 for different HBV genotypes, as compared to the first-generation DRW-

8 HBsAg assay. ${ }^{13}$ Indeed, among 271 HBsAg-positive patients tested in this study, DRW-

9 HBsAg v2.0 failed to detect HBsAg in only two cases, both containing a low level of HBsAg $10 \quad(<1.0 \mathrm{UI} / \mathrm{mL})$.

11 The genetic variability of the S gene can impair the diagnostic performance of HBsAg 12 assays, but the frequency of such variants in HBV-infected patients is not well established 13 and varies according to the HBV endemicity. ${ }^{14}$ We confirmed here the manufacturer's claim 14 that DRW-HBsAg v2.0 was able to detect HBsAg in patients infected with HBV variants 15 bearing various amino acid substitutions or combinations of substitutions in this region 16 (Table 2).

Assay sensitivity is a key criterion for large-scale HBsAg testing. However, test specificity is also crucial because it influences the requirement for result confirmation in

19 areas where resources for such confirmation are likely to be limited. In this study, we evaluated the specificity of DRW-HBsAg v2.0 in a large number of HBsAg-negative samples

21 ( $n=\underline{1497}$ overall). Our results showing that specificity of the assay was $\geq 98.0 \%$ indicated an effective balance between specificity and sensitivity. Specificity was optimal with visual

23 reading in our experiments. Overall, as shown in Table 3, visual reading was found to be 24 more reliable than automatic readout by means of ESE-Quant Lateral Flow Reader, which 25 needs to be further optimized. 
In conclusion, our study shows that the new, second version of the DRW-HBsAg rapid test is a simple, rapid, easy-to-run and highly sensitive assay that can be used in both

3 high- and low-risk populations for the diagnosis of HBsAg carriage with a $99.3 \%$ accuracy.

4 Thus, RDTs appear as promising new tools for large-scale screening and diagnosis of HBV

$5 \quad$ infection in the clinical setting.

6

7 FUNDING

8

9 The DRW-HBsAg v2.0 assay kits were kindly provided by Diagnostics for the Real 10 World $^{\mathrm{TM}}$, Ltd, Sunnyvale, California USA.

\section{COMPETING INTERESTS}

13

T.L. and L.N. are scientists employed by Diagnostics for the Real World Ltd (DRW);

15 H.L, in addition to her academic position, is also the President and CEO of DRW. The other 16 authors have no conflict of interest to disclose.

19 Patients gave their consent to the use of their residual samples. 


\section{REFERENCES}

1. Ott JJ, Stevens GA, Groeger J, Wiersma ST. Global epidemiology of hepatitis B virus infection: New estimates of age-specific HBsAg seroprevalence and endemicity. Vaccine. 2012.

2. Fattovich G, Bortolotti F, Donato F. Natural history of chronic hepatitis B: special emphasis on disease progression and prognostic factors. J Hepatol. 2008;48:335-52.

3. Meffre C, Le Strat Y, Delarocque-Astagneau E, Dubois F, Antona D, Lemasson JM, et al. Prevalence of hepatitis B and hepatitis C virus infections in France in 2004: social factors are important predictors after adjusting for known risk factors. J Med Virol. 2010;82:546-55.

4. Scheiblauer H, El-Nageh M, Diaz S, Nick S, Zeichhardt H, Grunert HP, et al. Performance evaluation of 70 hepatitis B virus (HBV) surface antigen (HBsAg) assays from around the world by a geographically diverse panel with an array of HBV genotypes and HBsAg subtypes. Vox Sang. 2010;98:403-14.

5. Sonneveld MJ, Rijckborst V, Boucher CA, Zwang L, Beersma MF, Hansen BE, et al. A comparison of two assays for quantification of Hepatitis B surface Antigen in patients with chronic hepatitis B. J Clin Virol. 2011.

6. Wursthorn K, Jaroszewicz J, Zacher BJ, Darnedde M, Raupach R, Mederacke I, et al. Correlation between the Elecsys HBsAg II assay and the Architect assay for the quantification of hepatitis B surface antigen (HBsAg) in the serum. J Clin Virol. 2011;50:292-6.

7. Chevaliez S, Bouvier-Alias M, Pawlotsky JM. Performance of the Abbott real-time PCR assay using m2000sp and m2000rt for hepatitis C virus RNA quantification. J Clin Microbiol. 2009;47:1726-32. 
1 8. Pallier C, Rodriguez C, Brillet R, Nordmann P, Hezode C, Pawlotsky JM. Complex dynamics of hepatitis B virus resistance to adefovir. Hepatology. 2009;49:50-9.

3 9. Pichoud C, Seigneres B, Wang Z, Trepo C, Zoulim F. Transient selection of a hepatitis B virus polymerase gene mutant associated with a decreased replication capacity and famciclovir resistance. Hepatology. 1999;29:230-7.

10. Stuyver L, De Gendt S, Van Geyt C, Zoulim F, Fried M, Schinazi RF, et al. A new genotype of hepatitis B virus: complete genome and phylogenetic relatedness. J Gen Virol. 2000;81:67-74.

11. Servant-Delmas A, Mercier M, El Ghouzzi MH, Girault A, Bouchardeau F, Pillonel J, et

12. Kettler H, White $\mathrm{K}$, Hawkes S. Mapping the landscape of diagnostics for sexually al. National survey of hepatitis B virus (HBV) polymorphism in asymptomatic HBV blood donors from 1999 to 2007 in France. Transfusion. 2010;50:2607-18. transmitted infections. In: WHO/TDR, editor. Geneva2004.

13. Lin YH, Wang Y, Loua A, Day GJ, Qiu Y, Nadala EC, Jr., et al. Evaluation of a new hepatitis B virus surface antigen rapid test with improved sensitivity. J Clin Microbiol. 2008;46:3319-24.

14. Hsu HY, Chang MH, Ni YH, Chen HL. Survey of hepatitis B surface variant infection in children 15 years after a nationwide vaccination programme in Taiwan. Gut. 2004;53:1499-503. 
Table 1. Analytical sensitivity of DRW-HBsAg v2.0, according to the HBV genotype (using Architect HBsAg assay as a comparator).

\begin{tabular}{|l|c|c|}
\hline HBV genotype & $\mathrm{N}$ & $\begin{array}{c}\text { Mean } \pm \text { SD lowest HBsAg level } \\
\text { detected }(\mathrm{IU} / \mathrm{mL})\end{array}$ \\
\hline Genotype A & 5 & $0.38 \pm 0.12$ \\
\hline Genotype B & 4 & $0.52 \pm 0.17$ \\
\hline Genotype C & 4 & $0.30 \pm 0.07$ \\
\hline Genotype D & 4 & $0.40 \pm 0.10$ \\
\hline Genotype E & 4 & $0.97 \pm 0.26$ \\
\hline
\end{tabular}


Table 2. HBsAg titers (Architect HBsAg assay) in the 20 blood donors from group C with amino acid substitutions in the major hydrophilic region (MHR) containing the "a" determinant of the $\mathrm{S}$ gene.

\begin{tabular}{|c|c|c|c|}
\hline Blood donors & Genotype & $\begin{array}{c}\text { HBsAg titer } \\
\left(\log _{10}\right. \\
\text { IU } / \mathrm{mL}) \\
\end{array}$ & Amino acid substitution(s) in the MHR \\
\hline 1 & $\mathrm{E}$ & 4.1 & D144E \\
\hline 2 & $\mathrm{D}$ & 2.5 & T131I \\
\hline 3 & $\mathrm{D}$ & 0.6 & T131N, M133I, T134H \\
\hline 4 & $\mathrm{C}$ & 3.9 & I126N \\
\hline 5 & $\mathrm{D}$ & 2.8 & T118V, A128V, Q129L, S171F, W172*stop \\
\hline 6 & A & 3.9 & M133T \\
\hline 7 & $\mathrm{D}$ & 0.7 & $\begin{array}{c}\text { Q101R, M103I, T118K, S143L, F158L, } \\
\text { W172L }\end{array}$ \\
\hline 8 & $\mathrm{D}$ & 3.7 & Y134N \\
\hline 9 & B & 3.3 & P120S, F134I \\
\hline 10 & $\mathrm{~B}$ & 2.9 & $\mathrm{~T} 126 \mathrm{~A}$ \\
\hline 11 & A & 3.4 & Q129H, D144A \\
\hline 12 & $\mathrm{D}$ & 2.3 & T118A \\
\hline 13 & B & 4.3 & G129H \\
\hline 14 & $\mathrm{D}$ & 1.8 & G130R \\
\hline 15 & $\mathrm{D}$ & 2.4 & G130R \\
\hline 16 & $E$ & 4.0 & G145R \\
\hline 17 & $\mathrm{E}$ & 2.8 & S143L \\
\hline 18 & B & -0.9 & M133T, T116N \\
\hline 19 & $\mathrm{E}$ & 3.3 & G145A \\
\hline 20 & A & $>5.4$ & T116N \\
\hline
\end{tabular}


Table 3. Visual reading versus automatic readouts by means of ESE-Quant Lateral Flow Reader for HBsAg detection with DRW-HBsAg v2.0 in the different study groups.

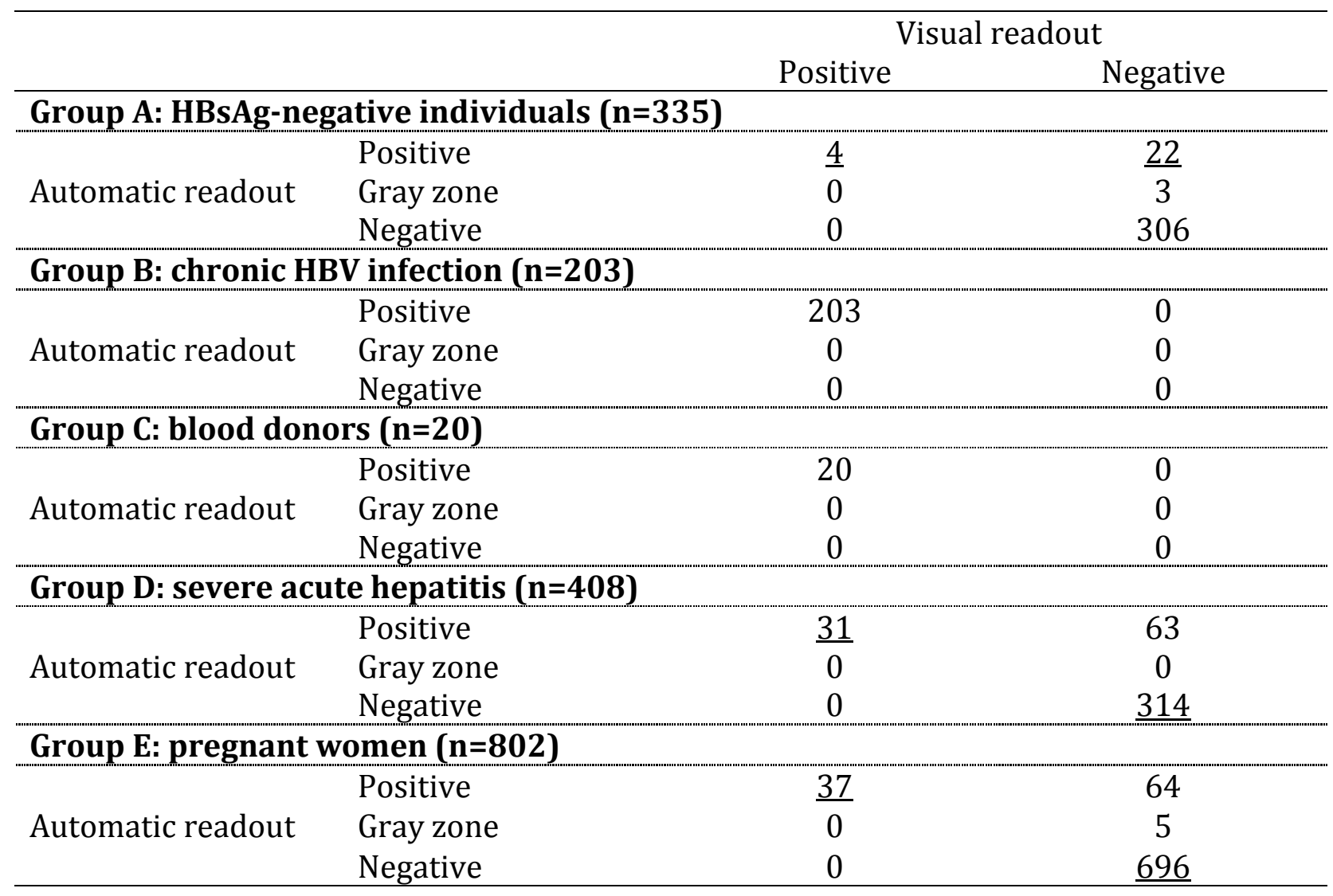

